\title{
Survivorship and Severe Complications Are Worse for Octogenarians and Elderly Patients with Pelvis Fractures as Compared to Adults: Data from the National Trauma Data Bank
}

\author{
Amir Matityahu, ${ }^{1}$ Joshua Elson, ${ }^{2}$ Saam Morshed, ${ }^{1}$ and Meir Marmor ${ }^{1}$ \\ ${ }^{1}$ Orthopaedic Trauma Institute, San Francisco General Hospital, University of California, San Francisco, $255023 r d$ Street, \\ Building 9, 2nd Floor, San Francisco, CA 94110, USA \\ ${ }^{2}$ Medical School for International Health, Ben-Gurion University of the Negev, Beer Sheba, Israel
}

Correspondence should be addressed to Amir Matityahu, matityahua@orthosurg.ucsf.edu

Received 3 April 2012; Revised 20 September 2012; Accepted 4 October 2012

Academic Editor: E. M. Lewiecki

Copyright ( $) 2012$ Amir Matityahu et al. This is an open access article distributed under the Creative Commons Attribution License, which permits unrestricted use, distribution, and reproduction in any medium, provided the original work is properly cited.

\begin{abstract}
Purpose. This study examined whether octogenarians and elderly patients with pelvic fractures have a different risk of complication and mortality as compared to adults. Methods. Data was gathered from the National Trauma Data Bank from 2002 to 2006 . There were 32,660 patients $18-65,6,408$ patients $65-79$, and 5,647 patients $\geq 80$ years old with pelvic fractures. Descriptive statistics and bivariate and multivariate analyses were performed with the adult population as a referent. Results. Multivariate analysis showed 4.7-fold higher odds of death and 4.57 odds of complications in the octogenarian group after a pelvic fracture compared to adults. The elderly had 1.81-fold higher odds of death and 2.18-fold higher odds of severe complications after sustaining a severe pelvic fracture relative to adults. An ISS $\geq 16$ yielded 15.1 -fold increased odds of mortality and 18.3 -fold higher odds of severe complications. Hypovolemic shock had 7.65-fold increased odds of death and 6.31-fold higher odds of severe complications. Between the ages of 18 and 89 years, there is approximately a 1\% decrease in survivorship every 10 years. Conclusions. This study illustrates that patients older than 80 years old with pelvis fractures have a higher mortality and complications rate than elderly or adult patients.
\end{abstract}

\section{Introduction}

Pelvic fractures comprise less than $5 \%$ of all fractures in octogenarians. However, fractures of the pelvis constitute up to $23 \%$ of admissions to level I trauma centers [1]. Similar to adults, octogenarians have pelvic fractures that can be associated with high-energy trauma and injury to other physiological systems that may lead to an increased incidence of complications and mortality [1]. Multiple fractures and organ damage may occur with low velocity injury because of the osteoporotic nature of the octogenarian skeleton and the increased association with chronic comorbidities and sarcopenia $[2,3]$. Thus, an elderly person presenting with a pelvic fracture should be evaluated early for having a multiorgan injury with an increased potential for harm, complications, and death. Previous studies on octogenarian pelvic fractures analyzed the elderly population as a whole, including both the elderly (65-79 years old) and the octogenarians ( $\geq 80$ years old) $[1,4]$. Low velocity injuries in the elderly have been the focus studies that evaluated patients with osteoporosis and pelvis fractures [5-7].

Patients older than 80 comprise a period of life that is fraught with multiple comorbidities that are managed by their primary care physician. Decline in the reproductive, cardiovascular, and skeletal systems, as well as alterations in body composition during this stage of life, can often contribute to varying responses to injury $[3,8]$. Physiological changes in the elderly lead to a theoretical decreased ability to withstand the effect of traumatic injury. Physiologic changes include a decrease in weight, lean body mass, muscle size, 
and bone mass [8]. Moreover, there is a decrease in blood pressure, blood volume, hematocrit cardiovascular, and lung vital capacity [9]. Thus, depending on the placement of an elderly person on the physiological curve, he or she may respond to trauma differently than an adult.

The authors hypothesized that octogenarian patients with pelvic fractures have a higher risk of complications and mortality as compared to younger elderly and adult patients after admission to a trauma center. Because of the relative rarity of high velocity pelvic fractures in elderly and octogenarian patients, data was collected from the National Trauma Data Bank (NTDB).

\section{Materials and Methods}

We identified the study populations that were entered into the National Trauma Data Bank (NTDB version 7.1). This NTDB version contained data from over 900 United States trauma centers. There were over 2.7 million patient records from the years 2002 to 2006 that were entered into the NTDB. The NTDB contains patient data compiled from medical records before, during, and after admission. This information is submitted to the American College of Surgeons for quality control and maintenance.

The NTDB reports all injuries by using the International Classification of Diseases, 9th Revision, Clinical Modification (ICD-9-CM) diagnostic codes. The data was imported and merged into a single dataset from the 13 NTDB files using SAS version 9.2 (SAS Institute, Cary, NC). Abbreviated Injury Scale (AIS) scores for lower extremities were linked to a pelvic fracture code (see later). Linking to the pelvic fracture code ensured that AIS values were recorded for only pelvic injuries.

The initial NTDB population consisted of over 2.7 million entries. For the purpose of this study, all burn or penetrating injuries were excluded reducing the group to1.7 million patients. If a patient's multiple ICD-9 DCODE (diagnosis codes) entries contained at least one of the following codes, the patient was considered to have a pelvic fracture: $808.2,808.3,808.4,808.41,808.42,808.43,808.49$, $808.5,808.51,808.52,808.53,808.59,808.8$, and 808.9. Acetabular fractures were excluded from the study. If the ICD-9 codes were 808.2, 808.41, 808.42, 808.43, 808.49, or 808.8 , the pelvic fractures were closed pubis, ilium, ischium, multiple, other, or unspecified, respectively. If the ICD-9 codes were 808.3, 808.51, 808.52, 808.53, 808.59, or 808.9, the pelvic fractures were open pubis, ilium, ischium, multiple, other, or unspecified, respectively. Those entries without a pelvic fracture were removed, giving a total of 54,459 patients with pelvic fractures.

In order to analyze the elderly population and compare it to the adult population, children aged 17 years and younger were excluded yielding a study population of 45,081 patients. This final study population was subdivided into octogenarian, defined as all patients older than 79 years, elderly, defined as ages 65 to 79 years old, and adults, defined to be ages 18 to 64 years old. This subdivision was performed because of many previous studies that evaluated strength, performance, and outcomes in groups younger or older than 80 years old [10-13].

The main outcomes of interest were mortality and severe complication. A severe complication was defined as having renal failure, acute respiratory distress syndrome (ARDS), or a pulmonary embolism recorded in the NTDB. Analysis of prehospital risk factors was considered to determine the association with the main outcome variables of mortality and severe complications. These risk factors included sex, race, age, arrival in shock (systolic blood pressure less than $90 \mathrm{mmHg}$ ), head injury (a positive head computed tomography), injury severity score (ISS), and mechanism of injury.

2.1. Statistical Analysis. All statistical analyses were conducted using SAS. Descriptive statistics were performed on the entire study population. To determine associations between risk factors and the main outcomes of interest, bivariate analysis was conducted between the main end points and each pre-hospital risk factor. Continuous covariates were dichotomized. Risk factors that were not already dichotomous were transformed into two mutually exclusive categories. For example, ISS became greater than or equal to 16 and less than 16. For this assessment, open fractures and unknown mechanisms of injury were excluded, yielding a study group of 31,475 .

A subpopulation of severe pelvic injuries was also created to determine if any octogenarian subgroup has better outcomes. For this population, an AIS of less than 3 and all patients with lower extremity fractures besides pelvic fractures were excluded. This created a study subgroup of 3,101 patients with isolated severe pelvic fractures.

For both the main study population and the subgroup of severe pelvic injury, prehospital risk factors were determined to be significant using the Mantel-Haenszel test. This method produced crude odds ratios and 95\% confidence intervals, and those variables of significance were included for multivariate analysis. Mechanism of injury was not included in the final multivariate analysis due to the inconsistency and unreliability of the data.

Logistic regression analyses including those variables deemed to be of significance were performed to determine the association between the prehospital risk factors and the two main outcomes (death and severe complication). In order to assess the importance of age and outcome after sustaining a pelvic fracture, each model included a specific age group (octogenarian or elderly) as compared to adults as referent. The Hosmer-Lemeshow goodness-of-fit test was performed on each model to determine whether or not the observed event rates matched the expectant event rates. The $P$ value must be greater than 0.05 to indicate a good fit.

\section{Results}

3.1. Descriptive Data for the Whole Population. There were 45,081 individuals that matched the preliminary inclusion and exclusion criteria. Descriptive statistics of demographics, injury mechanism, injury severity, treatment, and complications are presented in Table 1. The study population was 
TABLE 1: Frequency distribution of characteristics for the entire population of pelvic fractures, $n=45,081$.

\begin{tabular}{|c|c|c|c|c|}
\hline \multirow[b]{2}{*}{ Variable } & \multicolumn{4}{|c|}{ Age group } \\
\hline & $\begin{array}{c}\text { Adults } \\
\text { (18-64 years) } \\
n(\%) \\
N=32,660 \\
\end{array}$ & $\begin{array}{c}\text { Elderly } \\
\text { (65-79 years) } \\
n(\%) \\
N=6,408\end{array}$ & $\begin{array}{c}\text { Octogenarian } \\
(\geq 80 \text { years }) \\
n(\%) \\
N=5,647\end{array}$ & $\begin{array}{c}\text { Total } \\
n(\%)\end{array}$ \\
\hline \multicolumn{5}{|l|}{ Gender } \\
\hline Male & $19,920(61.1)$ & $2,619(40.9)$ & $1,361(24.1)$ & $23,900(53.5)$ \\
\hline Female & $12,704(38.9)$ & $3,778(59.1)$ & $4,277(75.9)$ & $20,759(46.5)$ \\
\hline \multicolumn{5}{|l|}{ Race } \\
\hline Caucasian & $21,205(71.1)$ & $5,013(84.1)$ & $4,744(90.2)$ & $31,162(75.5)$ \\
\hline African American & $3,006(10.0)$ & $286(4.9)$ & $132(2.6)$ & $3,424(8.3)$ \\
\hline Asian/Pacific Islander & $583(1.9)$ & $128(2.2)$ & $63(1.3)$ & $774(1.9)$ \\
\hline Hispanic & $3,261(10.8)$ & $258(4.3)$ & $78(1.6)$ & $3,597(8.7)$ \\
\hline Native American & $218(0.8)$ & $21(0.3)$ & $1(0.1)$ & $240(0.6)$ \\
\hline Other & $1,631(5.4)$ & $282(4.2)$ & $212(4.2)$ & $2,095(5.0)$ \\
\hline \multicolumn{5}{|l|}{ Survival } \\
\hline Survived & $29,622(91.2)$ & $5,528(86.6)$ & $4,895(86.8)$ & $40,045(90.0)$ \\
\hline Died & $2,867(8.8)$ & $855(13.4)$ & $743(13.2)$ & $4,465(10.0)$ \\
\hline \multicolumn{5}{|l|}{ Severe complication* } \\
\hline Yes & $3,715(11.4)$ & $1,032(16.2)$ & $819(14.5)$ & $5,566(12.5)$ \\
\hline No & $28,783(88.6)$ & $5,352(83.8)$ & $4,819(85.5)$ & $38,954(87.5)$ \\
\hline \multicolumn{5}{|l|}{ Fracture type } \\
\hline Open & $1,456(4.5)$ & $106(1.7)$ & $40(0.7)$ & $1,602(3.6)$ \\
\hline Closed & $31,189(95.5)$ & $6,301(98.3)$ & $5,606(99.3)$ & $43,096(96.4)$ \\
\hline \multicolumn{5}{|l|}{ Fracture location } \\
\hline Ilium & $4,370(13.9)$ & $677(10.7)$ & $391(7.0)$ & $5,438(12.6)$ \\
\hline Ischium & $1,332(4.2)$ & $312(5.0)$ & $236(4.2)$ & $1,880(4.3)$ \\
\hline Pubis & $12,977(41.4)$ & $2,822(44.7)$ & $2,695(48.0)$ & $18,494(42.7)$ \\
\hline Multiple & $2,040(6.5)$ & $248(3.9)$ & $127(2.3)$ & $2,415(5.6)$ \\
\hline Unspecified & $2,677(8.5)$ & $506(8.0)$ & $422(7.5)$ & $3,605(8.3)$ \\
\hline Other & $7,968(25.5)$ & $1,749(27.7)$ & $1,741(31.0)$ & $11,458(26.5)$ \\
\hline \multicolumn{5}{|c|}{ Systolic blood pressure (mmHg) } \\
\hline$<90$ & $5,389(16.5)$ & $1,093(17.1)$ & $936(16.6)$ & $7,418(16.6)$ \\
\hline $90-139$ & $18,823(57.6)$ & $2,691(42.0)$ & $1,914(33.9)$ & $23,428(52.4)$ \\
\hline $140+$ & $8,448(25.9)$ & $2,624(40.9)$ & $2,797(49.5)$ & $13,869(31.0)$ \\
\hline \multicolumn{5}{|l|}{$\mathrm{MOI}^{* *}$} \\
\hline Motor vehicle & $12,832(39.3)$ & $1,774(27.7)$ & $946(16.7)$ & $15,552(34.8)$ \\
\hline Motorcycle & $2,961(9.1)$ & $93(1.5)$ & $9(0.1)$ & $3,063(6.8)$ \\
\hline Pedestrian & $666(2.0)$ & $92(1.4)$ & $35(0.6)$ & $793(1.8)$ \\
\hline Crush & $870(2.7)$ & $143(2.2)$ & $41(0.7)$ & $1,054(2.4)$ \\
\hline High fall & $3,166(9.7)$ & $709(11.1)$ & $952(16.9)$ & $4,827(10.8)$ \\
\hline Low fall & $2,067(6.3)$ & $2,091(32.6)$ & $2,801(49.6)$ & $6,959(15.6)$ \\
\hline Unknown & $10,098(30.9)$ & $1,506(23.5)$ & $863(15.4)$ & $12,467(27.8)$ \\
\hline \multicolumn{5}{|l|}{$\mathrm{AIS}^{\dagger}$ of pelvis } \\
\hline None & $22,266(68.2)$ & $4,413(68.9)$ & $3,828(67.8)$ & $30,507(68.2)$ \\
\hline 1 & $108(0.3)$ & $9(0.1)$ & $9(0.1)$ & $126(0.3)$ \\
\hline 2 & $5,922(18.1)$ & $1,256(19.6)$ & $1,237(21.9)$ & $8,415(18.8)$ \\
\hline 3 & $3,550(10.9)$ & $623(9.7)$ & $546(9.7)$ & $4,719(10.6)$ \\
\hline 4 & $617(1.9)$ & $83(1.3)$ & $15(0.3)$ & $715(1.6)$ \\
\hline 5 & $197(0.6)$ & $24(0.4)$ & $12(0.2)$ & $233(0.5)$ \\
\hline 6 & $0(0.0)$ & $0(0.0)$ & $0(0.0)$ & $0(0.0)$ \\
\hline
\end{tabular}


Table 1: Continued.

\begin{tabular}{|c|c|c|c|c|}
\hline \multirow[b]{2}{*}{ Variable } & \multicolumn{4}{|c|}{ Age group } \\
\hline & 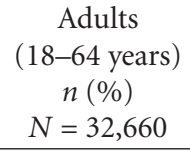 & $\begin{array}{c}\text { Elderly } \\
\begin{array}{c}\text { (65-79 years) } \\
n(\%) \\
N=6,408 \\
\end{array}\end{array}$ & $\begin{array}{c}\text { Octogenarian } \\
(\geq 80 \text { years }) \\
n(\%) \\
N=5,647\end{array}$ & $\begin{array}{l}\text { Total } \\
n(\%)\end{array}$ \\
\hline \multicolumn{5}{|l|}{ ISS $^{\dagger \dagger}$} \\
\hline$<16$ & $14,979(45.9)$ & $3,972(62.0)$ & $4,333(76.7)$ & $23,284(52.1)$ \\
\hline$\geq 16$ & $17,681(54.1)$ & $2,436(38.0)$ & $1,314(23.3)$ & $21,431(47.9)$ \\
\hline \multicolumn{5}{|l|}{ Acute respiratory stress syndrome } \\
\hline Yes & $668(2.1)$ & $105(1.6)$ & $63(1.1)$ & $836(1.9)$ \\
\hline No & $31,992(97.9)$ & $6,303(98.4)$ & $5,584(98.9)$ & $43,879(98.1)$ \\
\hline \multicolumn{5}{|l|}{ Renal failure } \\
\hline Yes & $281(0.9)$ & $105(1.6)$ & $59(1.0)$ & $445(1.0)$ \\
\hline No & $32,379(99.1)$ & $6,303(98.4)$ & $5,588(99.0)$ & $44,270(99.0)$ \\
\hline \multicolumn{5}{|l|}{ Pulmonary embolism } \\
\hline Yes & $199(0.6)$ & $52(0.8)$ & $26(0.5)$ & $277(0.6)$ \\
\hline No & $32,461(99.4)$ & $6,356(99.2)$ & $5,621(99.5)$ & $44,438(99.4)$ \\
\hline \multicolumn{5}{|l|}{ ICU stay } \\
\hline$<1$ week & $27,615(84.6)$ & $5,511(86.0)$ & $5,224(92.5)$ & $38,350(85.8)$ \\
\hline$\geq 1$ week & $5,045(15.4)$ & $897(14.0)$ & $423(7.5)$ & $6,365(14.2)$ \\
\hline \multicolumn{5}{|l|}{ Hospital stay } \\
\hline$<1$ week & $15,731(48.2)$ & $3,574(55.8)$ & $3,848(68.1)$ & $23,153(51.8)$ \\
\hline$\geq 1$ week & $16,929(51.8)$ & $2,834(44.2)$ & $1,799(31.9)$ & $21,562(48.2)$ \\
\hline \multicolumn{5}{|l|}{ Major procedure } \\
\hline CRIF & $22(0.1)$ & $3(0.1)$ & $0(0.0)$ & $25(0.1)$ \\
\hline ORIF & $153(0.5)$ & $12(0.2)$ & $9(0.2)$ & $174(0.4)$ \\
\hline Closed dislocation reduction & $130(0.4)$ & $3(0.1)$ & $1(0.0)$ & $134(0.3)$ \\
\hline Open dislocation reduction & $142(0.4)$ & $11(0.2)$ & $1(0.0)$ & $154(0.3)$ \\
\hline Other & $5,193(15.9)$ & $450(7.0)$ & $92(1.6)$ & $5,735(12.8)$ \\
\hline No major procedure & $27,020(82.7)$ & $5,929(92.4)$ & $5,544(98.2)$ & $38,493(86.1)$ \\
\hline
\end{tabular}

divided into octogenarian of more than 79 years of age $(n=$ $5,647)$, elderly between the ages of 65 and $79(n=6,408)$, and adults between the ages of 18 and $64(n=32,660)$. Males constituted $53.5 \%$ of the group. Adults had more males $(61.1 \%)$ than the elderly $(40.9 \%)$ or octogenarian (24.1\%) groups. Most of the individuals were reported to be Caucasian (75.5\%), with Hispanics (8.7\%) and African Americans ( $8.3 \%$ ) being the next largest ethnic groups. There was a marked increase in the percent of Caucasian patients in the octogenarian group $(90.2 \%)$ relative to the adult group $(71.1 \%)$. For the total population, the survival rate after sustaining a pelvis fracture was $90.0 \%$. When separated by age group, adults with pelvis fractures had the best survival $(91.2 \%)$. The elderly and octogenarian with pelvis fractures had worse survival relative to adults $(86.6 \%$ and $86.8 \%$, resp.). At least one severe complication occurred in $12.5 \%$ of the total population. The elderly had the highest percentage of complications (16.2\%) relative to adults $(11.4 \%)$ and octogenarians $(14.5 \%)$. The percent of patients that survived by age group for the whole population is presented in Figure 1.

Most of the pelvic fractures were closed (96.4\%). However, open fractures occurred in $4.5 \%$ of adults and only $0.7 \%$ of octogenarian patients. Pubic rami fractures had the highest prevalence $(42.7 \%)$, with the octogenarian patients having the highest percentage $(48 \%)$ relative to the elderly $(44.7 \%)$ and adults $(41.4 \%)$. The most common known mechanism of injury was motor vehicle accident $(34.8 \%)$, with low-energy fall (15.6\%) and high-energy fall (10.8\%) following. As expected, the octogenarian patients had a high rate of low energy falls $(49.6 \%)$ relative the elderly $(32.6 \%)$ and adult $(6.3 \%)$ patients. A large percentage of the population had no mechanism of injury reported $(27.8 \%)$. These individuals were excluded from the final analysis if it 
TABLE 2: Multivariate logistic regression analysis for the entire population of closed pelvic fractures using predictors upon arrival to the emergency department with the outcomes death and severe complication (odds ratios and 95\% confidence intervals).

\begin{tabular}{|c|c|c|}
\hline \multirow{3}{*}{ Model predictors } & \multicolumn{2}{|c|}{ Outcome } \\
\hline & Death & Severe complication* \\
\hline & $n=31,475$ & $n=31,475$ \\
\hline Adult (18-64 years) & Referent & Referent \\
\hline Elderly (65-79) & $2.35(2.10-2.62)$ & $2.19(1.98-2.42)$ \\
\hline $\begin{array}{l}\text { Octogenarian } \\
(\geq 80 \text { years })\end{array}$ & $3.60(3.19-4.04)$ & $2.87(2.57-3.21)$ \\
\hline Head injury & $1.62(1.42-1.84)$ & $1.59(1.41-1.79)$ \\
\hline ISS** $\geq 16$ & $10.4(9.26-11.7)$ & $9.54(8.62-10.6)$ \\
\hline Hosmer-Lemeshow $^{\dagger}$ & 0.34 & 0.08 \\
\hline \multicolumn{3}{|c|}{$\begin{array}{l}\text { * Severe complication is defined as having one or more of the following dur- } \\
\text { ing hospital course: pulmonary embolism, renal failure, acute respiratory } \\
\text { distress syndrome, or death. } \\
* * \text { ISS: injury severity score. }\end{array}$} \\
\hline
\end{tabular}

included the mechanism of injury. In terms of injury severity score (ISS), most patients had a score less than $16(52.1 \%)$. When divided by age, more octogenarian patients (76.7\%) had an ISS less than 16 compared to elderly $(62.0 \%)$ or adults (45.9\%). In terms of hemodynamic instability on arrival, the octogenarian group had a higher percentage of patients with systolic blood pressure (BP) greater than $140 \mathrm{mmHg}(49.5 \%)$ compared to the elderly (40.9\%) and the adults (25.9\%). The increase in blood pressure in octogenarians may be due to comorbid conditions previous to admission. For adults, elderly, and octogenarians, the rate of BP less than $90 \mathrm{mmHg}$ was similar $(16.5 \%-17.1 \%)$.

3.2. Multivariate Logistic Regression Analysis for the Whole Population. Variables that were found to be significant in the bivariate analysis were included in the final multiple logistic regression models for death and severe complication as outcomes using predictors upon arrivals to the emergency room. Adjusted odds ratios and $95 \%$ confidence intervals are presented in Table 2. As compared to the adult population, the elderly had 2.35 -fold increase in odds of death $(95 \%$ CI: 2.10-2.62) and 2.19-fold higher odds of severe complications (95\% CI: 1.98-2.42). Holding other variables constant, octogenarians had 3.60-fold higher odds of mortality (95\% CI: 3.19-4.04) and 2.87-fold higher odds of complications (95\% CI: 2.57-3.21) relative to adults. Sustaining a head injury had a 1.62-fold increase in the odds of death (CI: 1.421.84 ) and 1.59-fold higher odds of complication (95\% CI: 1.41-1.79). An ISS of greater than or equal to 16 increased the odds of death and complications to 10.4- (95\% CI: 9.2611.7 ) and 9.54- (95\% CI: 8.26-10.60) fold, respectively.

3.3. Severe Pelvic Fracture Subpopulation. A subgroup analysis was performed for patients determined to have a serious, isolated, and closed pelvic injury (AIS $\geq 3$ ). Table 3 demonstrates the descriptive statistics for this subpopulation

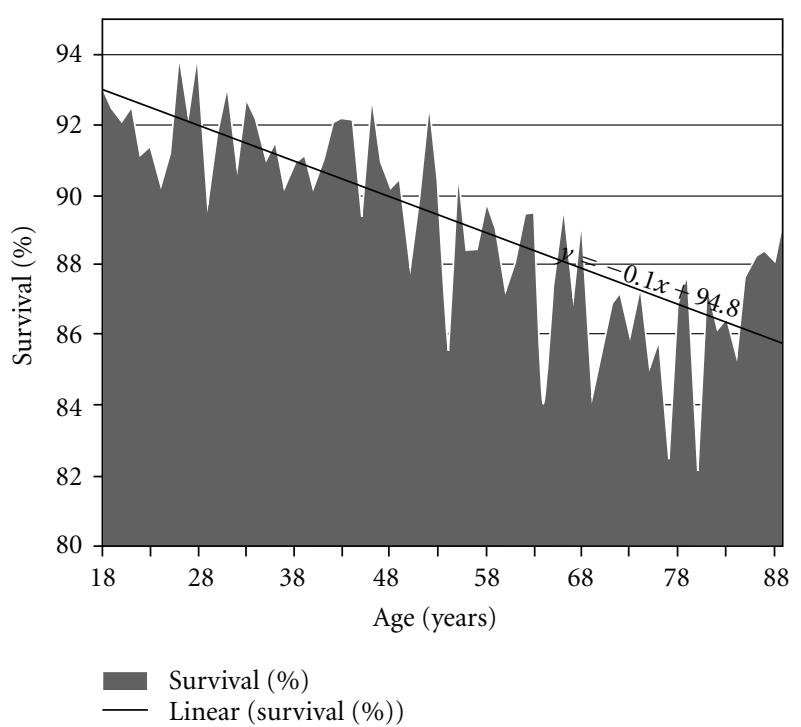

Figure 1: Percentage survival per age of patients with pelvis fractures.

$(n=3,101)$. There were minor differences in gender and race as compared to the whole population. For the variables survival and severe complication, adults survived slightly more $(94.2 \%)$ than the elderly population $(92.4 \%)$ and more than the octogenarian population $(90.3 \%)$. However, there were more severe complication rates in the elderly $(11.0 \%)$ and octogenarian (11.7\%) relative to the adult group $(8.0 \%)$. The most common mechanism of injury was low velocity fall for the octogenarian population $(56.2 \%)$ and the elderly population (45.4\%). However, the most common mechanism of injury for the adult population was motor vehicle accident (55.8\%). Similar to the whole population, the severe pelvic injury group demonstrated more octogenarian patients with an ISS less than $16(78.0 \%)$. In terms of hemodynamic instability on arrival, octogenarian patients had the highest percentage of patients with systolic blood pressure greater than $140 \mathrm{mmHg}(52.5 \%)$. The percentage of patients that survived and stayed in the hospital less than one week was largest in octogenarians (71.1\%) relative to elderly $(57.7 \%)$ and adults $(52.7 \%)$. By contrast, the octogenarian patients that survived had the highest rate of ICU stay less than one week (93.4\%) relative to the adults $(88.8 \%)$ and the elderly $(87.0 \%)$.

The severe pelvic fracture subpopulation data was analyzed using bivariate analysis (Table 4). Adults had a decrease in odds of death after sustaining a pelvic fracture. Individuals that suffered from hypovolemic shock, head injury, or ISS $\geq 16$, had an increase in odds of death and severe complications. Of all the reported mechanisms of injury, motor vehicle accident had 2.28-fold increased odds of death (95\% CI: 1.70-3.07) and 2.17-fold higher odds of severe complications (95\% CI: 1.68-2.80). Low energy falls had decreased odds of death (OR: 0.16, 95\% CI: 0.10-0.30) and severe complications (OR: 0.21, 95\% CI: 0.12-0.35).

Variables that were found to be significant in the bivariate analysis were included in the final multiple logistic regression 
TABLE 3: Frequency distribution of characteristics for the population with isolated, closed, and severe pelvic fractures (AIS $\geq 3$ ), $n=3,101$.

\begin{tabular}{|c|c|c|c|c|}
\hline \multirow[b]{2}{*}{ Variable } & \multicolumn{4}{|c|}{ Age group } \\
\hline & $\begin{array}{c}\text { Adults } \\
\text { (18-64 years) } \\
n(\%) \\
N=2,174\end{array}$ & $\begin{array}{c}\text { Elderly } \\
\text { (65-79 years) } \\
n(\%) \\
N=463 \\
\end{array}$ & $\begin{array}{c}\text { Octogenarian } \\
(\geq 80 \text { years }) \\
n(\%) \\
N=436\end{array}$ & $\begin{array}{c}\text { Total } \\
n(\%)\end{array}$ \\
\hline \multicolumn{5}{|l|}{ Gender } \\
\hline Male & $1,277(58.8)$ & $192(41.5)$ & $96(22.0)$ & $1,565(51.0)$ \\
\hline Female & $895(41.2)$ & $271(58.5)$ & $340(78.0)$ & $1,506(49.0)$ \\
\hline \multicolumn{5}{|l|}{ Race } \\
\hline Caucasian & $1,432(74.7)$ & $370(89.4)$ & $380(93.6)$ & $2,183(79.7)$ \\
\hline African American & $190(9.9)$ & $17(4.1)$ & $13(3.3)$ & $220(8.1)$ \\
\hline Asian/Pacific Islander & $24(1.2)$ & $4(1.0)$ & $1(0.2)$ & $29(1.0)$ \\
\hline Hispanic & $216(11.3)$ & $11(2.7)$ & $3(0.7)$ & $230(8.4)$ \\
\hline Native American & $7(0.4)$ & $1(0.2)$ & $0(0.0)$ & $8(0.3)$ \\
\hline Other & $48(2.5)$ & $11(2.6)$ & $9(2.2)$ & $68(2.5)$ \\
\hline \multicolumn{5}{|l|}{ Survival } \\
\hline Survived & $2,047(94.2)$ & $428(92.4)$ & $393(90.3)$ & $2,868(93.4)$ \\
\hline Died & $127(5.8)$ & $35(7.6)$ & $42(9.7)$ & $204(6.6)$ \\
\hline \multicolumn{5}{|l|}{ Severe complication* } \\
\hline Yes & $173(8.0)$ & $51(11.0)$ & $51(11.7)$ & $275(9.0)$ \\
\hline No & $2,001(92.0)$ & $412(89.0)$ & $384(88.3)$ & $2,797(91.0)$ \\
\hline \multicolumn{5}{|l|}{ Fracture location } \\
\hline Ilium & $266(12.2)$ & $40(8.6)$ & $24(5.5)$ & $330(10.7)$ \\
\hline Ischium & $58(2.7)$ & $10(2.2)$ & $11(2.5)$ & $79(2.6)$ \\
\hline Pubis & $1,230(56.6)$ & $309(66.7)$ & $323(74.1)$ & $1,862(60.6)$ \\
\hline Multiple & $315(14.5)$ & $50(10.8)$ & $21(4.8)$ & $386(12.6)$ \\
\hline Unspecified & $80(3.7)$ & $14(3.0)$ & $11(2.5)$ & $105(3.4)$ \\
\hline Other & $225(10.3)$ & $40(8.7)$ & $46(10.6)$ & $311(10.1)$ \\
\hline \multicolumn{5}{|c|}{ Systolic blood pressure (mmHg) } \\
\hline$<90$ & $208(9.6)$ & $63(13.6)$ & $44(10.1)$ & $315(10.2)$ \\
\hline $90-139$ & $1,354(62.3)$ & $209(45.2)$ & $163(37.4)$ & $1,726(56.2)$ \\
\hline $140+$ & $612(28.1)$ & $191(41.2)$ & $229(52.5)$ & $1,032(33.6)$ \\
\hline \multicolumn{5}{|l|}{$\mathrm{MOI}^{* *}$} \\
\hline Motor vehicle & $1,213(55.8)$ & $141(30.4)$ & $83(19.0)$ & $1,437(46.8)$ \\
\hline Motorcycle & $221(10.2)$ & $8(1.7)$ & $0(0.0)$ & $229(7.5)$ \\
\hline Pedestrian & $82(3.8)$ & $11(2.4)$ & $3(0.7)$ & $96(3.1)$ \\
\hline Crush & $121(5.6)$ & $21(4.5)$ & $8(1.8)$ & $150(4.9)$ \\
\hline High fall & $292(13.4)$ & $72(15.6)$ & $97(22.2)$ & $461(15.0)$ \\
\hline Low fall & $245(11.3)$ & $210(45.4)$ & $245(56.2)$ & $700(22.8)$ \\
\hline \multicolumn{5}{|l|}{$\mathrm{AIS}^{\dagger}$ of pelvis } \\
\hline 3 & $1,845(84.9)$ & $415(89.6)$ & 417 (95.6) & $2,677(87.1)$ \\
\hline 4 & $267(12.3)$ & $41(8.9)$ & $13(3.0)$ & $321(10.5)$ \\
\hline 5 & $62(2.8)$ & $7(1.5)$ & $6(1.4)$ & $75(2.4)$ \\
\hline 6 & $0(0.0)$ & $0(0.0)$ & $0(0.0)$ & $0(0.0)$ \\
\hline \multicolumn{5}{|l|}{$\mathrm{ISS}^{+\dagger}$} \\
\hline$<16$ & $936(43.0)$ & $289(62.4)$ & $340(78.0)$ & 1,565 \\
\hline$\geq 16$ & $1,238(57.0)$ & $174(37.6)$ & $96(22.0)$ & $1,508(49.1)$ \\
\hline \multicolumn{5}{|c|}{ Acute respiratory stress syndrome } \\
\hline Yes & $33(1.5)$ & $5(1.1)$ & $6(1.4)$ & $44(1.4)$ \\
\hline No & $2,141(98.5)$ & $458(98.9)$ & $430(98.6)$ & $3,029(98.6)$ \\
\hline
\end{tabular}


Table 3: Continued.

\begin{tabular}{|c|c|c|c|c|}
\hline \multirow[b]{2}{*}{ Variable } & \multicolumn{4}{|c|}{ Age group } \\
\hline & $\begin{array}{c}\text { Adults } \\
\text { (18-64 years) } \\
n(\%) \\
N=2,174\end{array}$ & $\begin{array}{c}\text { Elderly } \\
\text { (65-79 years) } \\
n(\%) \\
N=463\end{array}$ & $\begin{array}{c}\text { Octogenarian } \\
(\geq 80 \text { years }) \\
n(\%) \\
N=436\end{array}$ & $\begin{array}{c}\text { Total } \\
n(\%)\end{array}$ \\
\hline \multicolumn{5}{|l|}{ Renal failure } \\
\hline Yes & $11(0.5)$ & $9(1.9)$ & $1(0.2)$ & $21(0.7)$ \\
\hline No & $2,163(99.5)$ & $454(98.1)$ & $435(99.8)$ & $3,052(99.3)$ \\
\hline \multicolumn{5}{|l|}{ Pulmonary embolism } \\
\hline Yes & $10(0.5)$ & $5(1.1)$ & $2(0.5)$ & $17(0.6)$ \\
\hline No & 2,164 (99.5) & $458(98.9)$ & $434(99.5)$ & $3,056(99.4)$ \\
\hline \multicolumn{5}{|l|}{ ICU stay } \\
\hline$<1$ week & $1,931(88.8)$ & $403(87.0)$ & $407(93.4)$ & $2,741(89.2)$ \\
\hline$\geq 1$ week & $243(11.2)$ & $60(13.0)$ & $29(6.6)$ & $332(10.8)$ \\
\hline \multicolumn{5}{|l|}{ Hospital stay } \\
\hline$<1$ week & $1,145(52.7)$ & $264(57.0)$ & $310(71.1)$ & $1,719(55.9)$ \\
\hline$\geq 1$ week & $1,029(47.3)$ & $199(43.0)$ & $126(28.9)$ & $1,354(44.1)$ \\
\hline \multicolumn{5}{|l|}{ Major procedure } \\
\hline CRIF & $1(0.1)$ & $0(0.0)$ & $0(0.0)$ & $1(0.1)$ \\
\hline ORIF & $17(0.8)$ & $1(0.2)$ & $0(0.0)$ & $18(0.6)$ \\
\hline Closed dislocation reduction & $7(0.3)$ & $0(0.0)$ & $0(0.0)$ & $7(0.2)$ \\
\hline Open dislocation reduction & $16(0.7)$ & $0(0.0)$ & $0(0.0)$ & $16(0.5)$ \\
\hline Other & $551(25.3)$ & $45(9.7)$ & $14(3.2)$ & $610(19.8)$ \\
\hline No major procedure & $1,582(72.8)$ & $417(90.1)$ & $422(96.8)$ & $2,421(78.8)$ \\
\hline
\end{tabular}

models for death and severe complication as outcomes (Table 5). When controlling for pre-hospital conditions and using the adult group as a referent, the octogenarian group had 4.7-fold higher odds of death (95\% CI: 2.98-7.34) and 4.57-fold higher odd of complications (95\% CI: 3.01-6.96) after sustaining a pelvic fracture. Moreover, the elderly had 1.81-fold increase in odds of death (95\% CI: 1.16-2.80) and 2.18-fold increased odds of severe complications (95\% CI: 1.49-3.19) after sustaining a serious pelvic fracture. In this model, an ISS of greater than 16 yielded 15.1-fold increased odds of death (95\% CI: 8.76-26.61) and 18.3-fold increase in severe complications (95\% CI: 11.2-29.9). Hypovolemic shock also had 7.65-fold increase odds of death (95\% CI: 5.45-10.7) and 6.31-fold higher odds of severe complications (95\% CI: 4.60-8.66).

\section{Discussion}

This study found increased odds of complications and mortality in the octogenarian population with pelvic fractures as compared to younger elderly patients and adults. Multivariate logistic regression analysis showed that octogenarians had a large increase odds ratio of death even though the mechanisms of injury and ISS were less severe compared to adults.
The management of elderly and octogenarian patients with pelvis fractures is fraught with increased mortality relative to their adult counterparts. The numbers of patients older than 80 years are increasing, and they are enjoying a more active lifestyle. In light of their increased fragility and decreased reaction times, it is likely that they will continue to have an increase in the incidence of severe traumas [1, 14, 15]. Moreover, 69\% of patients older than 65 years of age have increased comorbidities on admission to the trauma center relative to their younger adult counterparts [16].

There are few studies that evaluate the outcomes of elderly patients with pelvis fractures [4-7, 17-21]. This study differs from previous studies regarding pelvic fractures in the elderly population by considering the octogenarian $(\geq 80$ years old) and young elderly (65-79 years old) populations in the United States that were admitted to trauma centers as separate groups. We have analyzed records gathered from the NTDB regarding pelvis fractures to characterize the risks of mortality and complications in 6,408 elderly and 5,647 octogenarians and compared them to 32,660 adults. Analysis of the data illustrates that relative to adults, octogenarians, more than elderly patients, had an increased odds ratio of mortality and severe complications. Commensurate with other research, this study found that for the total population 
TABLE 4: Bivariate analysis for the population with isolated, closed, and severe pelvic fractures (AIS $\geq 3$ ), comparing predictors upon arrival to the emergency department with the outcomes death and severe complication (odds ratios and 95\% confidence intervals), $n=31,475$.

\begin{tabular}{|c|c|c|}
\hline \multirow{2}{*}{ Predictors } & \multicolumn{2}{|c|}{ Outcome } \\
\hline & Death & Severe complication* \\
\hline Male & $1.04(0.78-1.38)$ & $1.25(0.98-1.61)$ \\
\hline Not Caucasian & $1.29(0.95-1.74)$ & $1.13(0.87-1.47)$ \\
\hline Adult (18-64 years) & $0.66(0.49-0.89)$ & $0.67(0.52-0.87)$ \\
\hline Elderly (65-79) & $1.18(0.81-1.72)$ & $1.31(0.95-1.81)$ \\
\hline $\begin{array}{l}\text { Octogenarian } \\
(>80 \text { years })\end{array}$ & $1.63(1.14-2.32)$ & $1.43(1.03-1.97)$ \\
\hline Hypovolemic shock & $8.43(6.20-11.50)$ & 6.85 (5.17-9.07) \\
\hline Head injury & $4.38(3.03-6.33)$ & $4.80(3.46-6.67)$ \\
\hline $\mathrm{ISS}^{\dagger} \geq 16$ & $13.0(7.90-21.5)$ & $15.1(9.61-23.7)$ \\
\hline Motor vehicle accident & $2.28(1.70-3.07)$ & $2.17(1.68-2.80)$ \\
\hline Motorcycle accident & $1.30(0.79-2.12)$ & $1.10(0.69-1.72)$ \\
\hline Fall from height & $0.63(0.40-1.00)$ & $0.75(0.51-1.10)$ \\
\hline Low energy fall & $0.16(0.10-0.30)$ & $0.21(0.13-0.35)$ \\
\hline Crush & $1.23(0.67-2.25)$ & $1.04(0.59-1.83)$ \\
\hline Pedestrian versus auto & $1.46(0.72-2.94)$ & $1.60(0.88-2.91)$ \\
\hline
\end{tabular}

${ }^{*}$ Severe complication is defined as having one or more of the following during hospital course: pneumonia, bacteremia, deep vein thrombosis, pulmonary embolism, renal failure, acute respiratory distress syndrome, or death.

${ }^{\dagger}$ ISS: injury severity score.

TABLE 5: Multivariate logistic regression analysis for the population with isolated, closed, and severe pelvic fractures (AIS $\geq 3$ ) using predictors upon arrival to the emergency department with the outcomes death and severe complication (odds ratios and 95\% confidence intervals).

\begin{tabular}{|c|c|c|}
\hline \multirow[b]{2}{*}{ Model predictors } & \multicolumn{2}{|c|}{ Outcome } \\
\hline & $\begin{array}{c}\text { Death } \\
n=3,101\end{array}$ & $\begin{array}{l}\text { Severe complication* } \\
\qquad n=3,101\end{array}$ \\
\hline Adult (18-64 years) & Referent & Referent \\
\hline Elderly (65-79) & $1.81(1.16-2.80)$ & $2.18(1.49-3.19)$ \\
\hline $\begin{array}{l}\text { Octogenarian } \\
\text { ( } \geq 80 \text { years })\end{array}$ & $4.70(2.98-7.38)$ & $4.57(3.01-6.96)$ \\
\hline Hypovolemic shock & $7.65(5.45-10.7)$ & $6.31(4.60-8.66)$ \\
\hline Head injury & $2.74(1.81-4.14)$ & $2.86(1.98-4.13)$ \\
\hline ISS $^{* *} \geq 16$ & $15.1(8.76-26.1)$ & $18.3(11.2-29.9)$ \\
\hline Hosmer-Lemeshow $^{\dagger}$ & 0.33 & 0.43 \\
\hline
\end{tabular}

${ }^{*}$ Severe complication is defined as having one or more of the following during hospital course: pulmonary embolism, renal failure, acute respiratory distress syndrome, or death.

$* *$ ISS: injury severity score.

${ }^{\dagger}$ Hosmer-Lemeshow $P$ value given for model's goodness of fit instead of odds ratio and $95 \%$ confidence interval.

with pelvic injuries admitted to trauma centers, hypovolemic shock, head injury, ISS $\geq 16$, and higher velocity mechanisms of injury have an increased risk of death [22]. In this study, and commensurate with other studies [1], low velocity falls were the most common mechanism of injury for elderly $(30 \%)$ and octogenarian (50\%) patients with pelvis fractures. In a study that surveyed falls in patients older than 65 , injury with ISS greater than 15 occurred in $32 \%$ of the elderly versus $15 \%$ in the young [23]. Moreover, they found that $27 \%$ of elderly patients and $14 \%$ of young patients had AIS scores attributed to the pelvis. The conclusion was that it could take lower velocity trauma in elderly patients to cause high severity injuries. However, in a study examining age-related outcomes that stratified patients who sustained blunt pelvic injury into more or less than 55 year old, the elderly and young had the same mechanism of injury that brought them to that tertiary care facility [24].

Overall, there was 10.4-fold increased odds ratio for the risk of death if the ISS was $\geq 16$. There were lower velocity mechanisms and a smaller percentage of patients with ISS $\geq 16$ in both the elderly $(38.0 \%)$ and octogenarian (23.3\%) relative to adults (54.1\%). Despite lower energy mechanisms and ISS, multivariate logistic regression analysis for the entire population showed that being an octogenarian had 3.6-fold increase in odds ratio of death relative to the adult population. Moreover, elderly patient's odds ratio of death was 2.35-fold higher relative to the adult population.

Patients with pelvis AIS $\geq 3$ were analyzed for complications and were associated with hypovolemic shock, head injury, and ISS $\geq 16$. More specifically, adults with AIS $\geq 3$ survived slightly more (94\%) then elderly (92\%) and octogenarians $(90.3 \%)$. The rest of the surviving octogenarian population had minimal complications and a decreased hospital length of stay relative to the elderly and adults. When analyzing the average percent survival relative to age, the trend was for decreasing in survival as age increased. More specifically, as patient's ages increased from 18 to 89 years, there is approximately a $1 \%$ decrease in survivorship per 10 years. That is, pelvic fracture patient survival decreases from $92.5 \%$ at age 20 to $85.5 \%$ at age 88 .

We also analyzed the percentage of major procedures performed. The elderly and octogenarian patients had less surgery relative to the adult population in spite of a higher complication and mortality rate. This finding was in contrast to recommendations that angiographic embolization should be performed if bleeding into the pelvis is found in the elderly patient regardless of haemodynamic instability [25].

Regarding hospital stay, we found that the elderly population that survived had a shorter hospitalization relative to their adult counterparts. This may be explained by the fact that the overwhelming number of elderly and octogenarian patients had pelvis fractures as a result of low velocity injuries. Moreover, these results underscore the importance of osteoporosis therapy in the prevention of pelvic and other osteoporotic fractures in the elderly and octogenarian populations.

The main strengths of the current study are that this is the largest cohort of elderly and octogenarian patients with pelvis fractures under investigation. Moreover, the representations of more than 900 academic and nonacademic centers of various trauma designation levels provide broad generalizability. However, this study also has few notable limitations. The National Trauma Data Bank is 
a convenience sample that contains data entered by many contributing United States hospitals and is not a total population database. Another limitation was that since the NTDB does not code separately for pelvic AIS, the pelvic AIS score was computed by excluding all patients with other lower extremity injuries from the lower extremity AIS score. This may have influenced the descriptive statistics. However, this allowed the comparison of similar injuries and to better isolate the effect of age. Finally, there could be interaction between variables that were not included in the model. These variables might not have been collected by the NTDB or may be latent factors not identified. Such discrepancies may have altered the final parameter estimates by either inflating or deflating their values. One potential limitation of the study is that we did not compare the comorbid conditions of the study sample to the entire NTDB. However, in a Canadian study, the authors found that more than $90 \%$ of octogenarians admitted to the emergency room with pelvis fractures had medical comorbidities [20]. Therefore, we can assume that our octogenarian patients also have similar comorbidities. However, we do not have similar data on the younger age group of patients and therefore could not include this information in this study. Another potential limitation of the study is that we did not include severe bleeding as a severe complication. This parameter is a cause of hemodynamic shock, but it is difficult to quantify and accurately report in a dataset like the NTDB. Therefore, it was not included in this study. Other limitations may include the fact that body mass index (BMI) can be a factor in the development of pulmonary embolism but may be protective of mortality in patients with pelvis fractures $[17,26]$. This data was not sufficiently present to include in our prediction models.

In conclusion, the results of this study illustrate that the patients older than 80 years with pelvis fractures have a much higher mortality and complications rate than patients younger than 80 years old. These results emphasize the need for continued focus and study of the elderly patient with a pelvis fracture.

\section{Conflict of Interests}

There are no financial relationships with any organizations that might have an interest in the submitted work in the previous 3 years for any of the authors. There are no relationships or activities that have influenced the submitted work. All authors were fully involved in the study and preparation of the paper, and the material within has not been submitted for publication elsewhere.

\section{References}

[1] T. A. Dechert, T. M. Duane, B. P. Frykberg, M. B. Aboutanos, A. K. Malhotra, and R. R. Ivatury, "Elderly patients with pelvic fracture: interventions and outcomes," American Surgeon, vol. 75, no. 4, pp. 291-295, 2009.

[2] J. A. Barrett, J. A. Baron, and M. L. Beach, "Mortality and pulmonary embolism after fracture in the elderly," Osteoporosis International, vol. 14, no. 11, pp. 889-894, 2003.
[3] G. D. Cartee, "Aging skeletal muscle: response to exercise," Exercise and Sport Sciences Reviews, vol. 22, pp. 91-120, 1994.

[4] I. Rossvoll and V. Finsen, "Mortality after pelvic fractures in the elderly," Journal of Orthopaedic Trauma, vol. 3, no. 2, pp. 115-117, 1989.

[5] D. Krappinger, C. Kammerlander, D. J. Hak, and M. Blauth, "Low-energy osteoporotic pelvic fractures," Archives of Orthopaedic and Trauma Surgery, vol. 130, no. 9, pp. 11671175, 2010.

[6] P. Kannus, M. Palvanen, S. Niemi, J. Parkkari, and M. Järvinen, "Epidemiology of osteoporotic pelvic fractures in elderly people in Finland: sharp increase in 1970-1997 and alarming projections for the new millennium," Osteoporosis International, vol. 11, no. 5, pp. 443-448, 2000.

[7] P. Kannus, M. Palvanen, J. Parkkari, S. Niemi, and M. Järvinen, "Osteoporotic pelvic fractures in elderly women," Osteoporosis International, vol. 16, no. 10, pp. 1304-1305, 2005.

[8] M. A. Rogers, J. M. Hagberg, W. H. Martin 3rd, A. A. Ehsani, and J. O. Holloszy, "Decline in VO2max with aging in master athletes and sedentary men," Journal of Applied Physiology, vol. 68, no. 5, pp. 2195-2199, 1990.

[9] A. L. Chen, S. C. Mears, and R. J. Hawkins, "Orthopaedic care of the aging athlete," The Journal of the American Academy of Orthopaedic Surgeons., vol. 13, no. 6, pp. 407-416, 2005.

[10] V. I. Kalapotharakos, K. Diamantopoulos, and S. P. Tokmakidis, "Effects of resistance training and detraining on muscle strength and functional performance of older adults aged 80 to 88 years," Aging Clinical and Experimental Research, vol. 22, no. 2, pp. 134-140, 2010.

[11] E. Sillanpää, A. Häkkinen, K. Punnonen, K. Häkkinen, and D. E. Laaksonen, "Effects of strength and endurance training on metabolic risk factors in healthy 40-65-year-old men," Scandinavian Journal of Medicine and Science in Sports, vol. 19, no. 6, pp. 885-895, 2009.

[12] N. D. Carter, K. M. Khan, H. A. McKay et al., "Communitybased exercise program reduces risk factors for falls in 65- to 75-year-old women with osteoporosis: randomized controlled trial," Canadian Medical Association Journal, vol. 167, no. 9, pp. 997-1004, 2002.

[13] T. Rantanen, P. Era, and E. Heikkinen, "Physical activity and the changes in maximal isometric strength in men and women from the age of 75 to 80 years," Journal of the American Geriatrics Society, vol. 45, no. 12, pp. 1439-1445, 1997.

[14] J. L. Kelsey, M. M. Prill, T. H. M. Keegan, C. P. Quesenberry, and S. Sidney, "Risk factors for pelvis fracture in older persons," American Journal of Epidemiology, vol. 162, no. 9, pp. 879-886, 2005.

[15] D. P. Beason, G. J. Dakin, R. R. Lopez, J. E. Alonso, F. A. Bandak, and A. W. Eberhardt, "Bone mineral density correlates with fracture load in experimental side impacts of the pelvis," Journal of Biomechanics, vol. 36, no. 2, pp. 219-227, 2003.

[16] D. J. McMahon, C. W. Schwab, and D. Kauder, "Comorbidity and the elderly trauma patient," World Journal of Surgery, vol. 20, no. 8, pp. 1113-1120, 1996.

[17] D. Prieto-Alhambra, F. F. Aviles, A. Judge et al., "Burden of pelvis fracture: a population-based study of incidence, hospitalisation and mortality," Osteoporosis International. In press.

[18] B. Ragnarsson and B. Jacobsson, "Epidemiology of pelvic fractures in a Swedish county," Acta Orthopaedica Scandinavica, vol. 63, no. 3, pp. 297-300, 1992. 
[19] G. Tosounidis, J. H. Holstein, U. Culemann, F. Holmenschlager, F. Stuby, and T. Pohlemann, "Changes in epidemiology and treatment of pelvic ring fractures in Germany: an analysis on data of German Pelvic Multicenter Study groups i and III (DGU/AO)," Acta Chirurgiae Orthopaedicae et Traumatologiae Cechoslovaca, vol. 77, pp. 450-456, 2010.

[20] G. Dodge and R. Brison, "Low-impact pelvic fractures in the emergency department," Canadian Journal of Emergency Medicine, vol. 12, no. 6, pp. 509-513, 2010.

[21] V. Breuil, C. H. Roux, J. Testa et al., "Outcome of osteoporotic pelvic fractures: an underestimated severity. Survey of 60 cases," Joint Bone Spine, vol. 75, no. 5, pp. 585-588, 2008.

[22] A. J. Starr, D. R. Griffin, C. M. Reinert et al., "Pelvic ring disruptions: prediction of associated injuries, transfusion requirement, pelvic arteriography, complications, and mortality," Journal of Orthopaedic Trauma, vol. 16, no. 8, pp. 553-561, 2002.

[23] D. A. Sterling, J. A. O'Connor, and J. Bonadies, "Geriatric falls: injury severity is high and disproportionate to mechanism," Journal of Trauma, vol. 50, no. 1, pp. 116-119, 2001.

[24] D. P. O’Brien, F. A. Luchette, S. J. Pereira et al., "Pelvic fracture in the elderly is associated with increased mortality," Surgery, vol. 132, no. 4, pp. 710-715, 2002.

[25] B. J. Kimbrell, G. C. Velmahos, L. S. Chan, D. Demetriades, G. J. Jurkovich, and J. A. Weigelt, "Angiographic embolization for pelvic fractures in older patients," Archives of Surgery, vol. 139, no. 7, pp. 728-733, 2004.

[26] C. Kabrhel, R. Varraso, S. Z. Goldhaber, E. B. Rimm, and C. A. Camargo, "Prospective study of BMI and the risk of pulmonary embolism in women," Obesity, vol. 17, no. 11, pp. 2040-2046, 2009. 


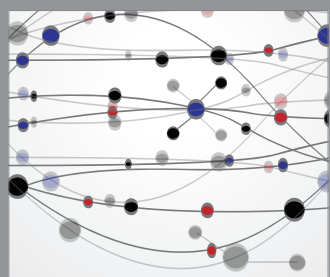

The Scientific World Journal
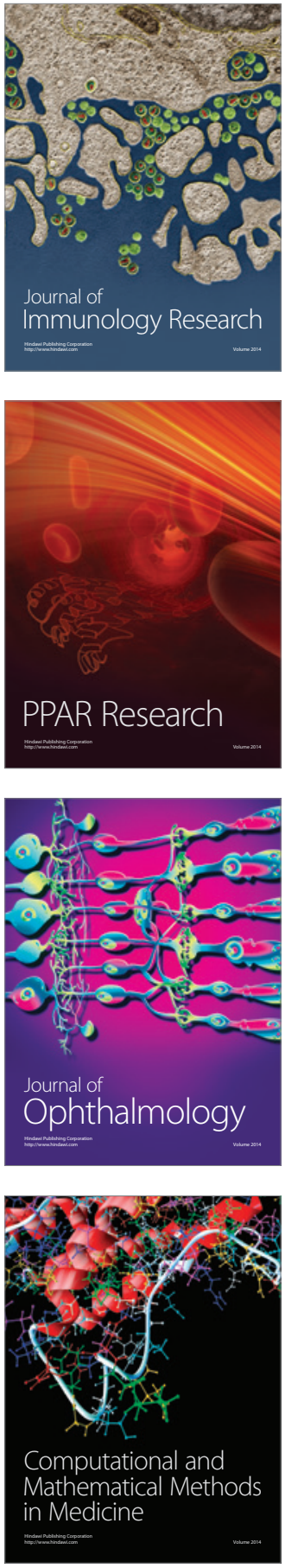

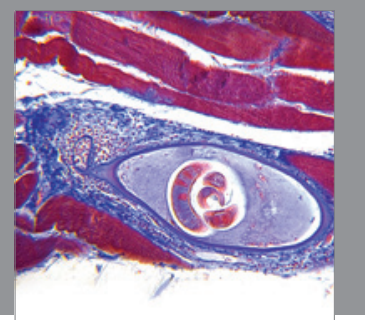

Gastroenterology

Research and Practice
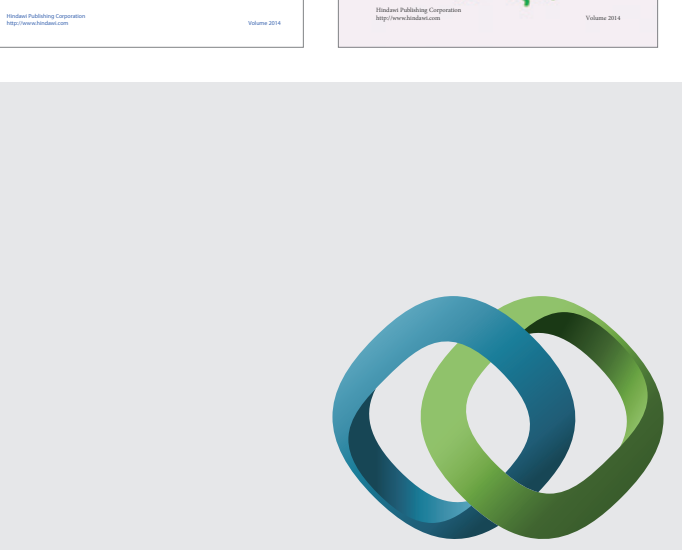

\section{Hindawi}

Submit your manuscripts at

http://www.hindawi.com
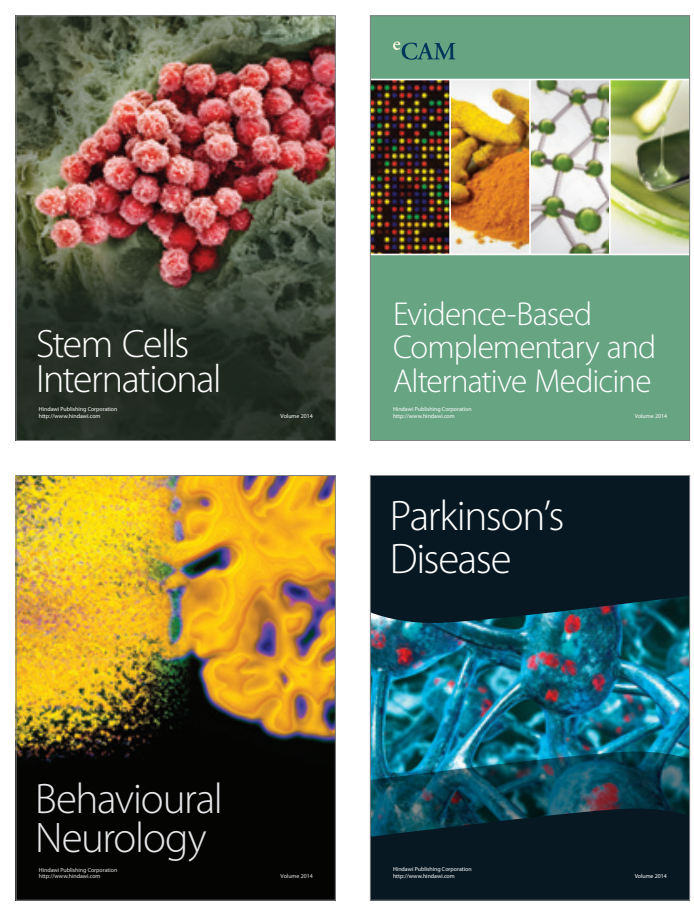

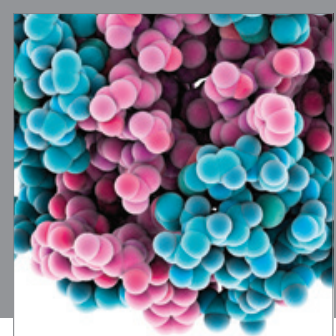

Journal of
Diabetes Research

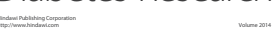

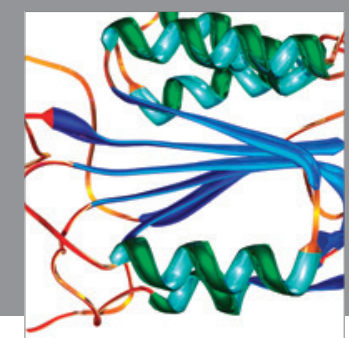

Disease Markers
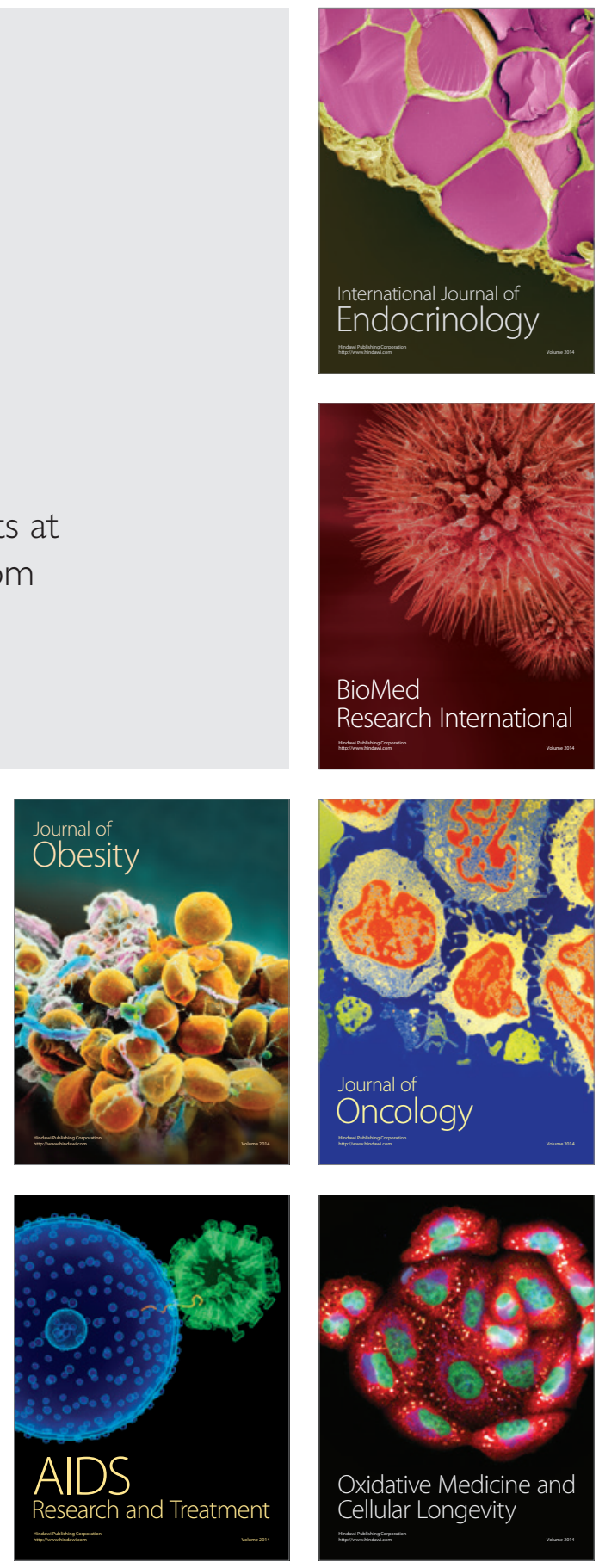